\title{
Interactive comment on "A Global Compilation of U-series Dated Fossil Coral Sea-level Indicators for the Last Interglacial Period (MIS 5e)" by Peter M. Chutcharavan and Andrea Dutton
}

\section{Peter M. Chutcharavan and Andrea Dutton}

chutcharavan@wisc.edu

Received and published: 13 February 2021

We thank Barbara Mauz for the manuscript suggestions and comments. The reason we did not cite Medina-Elizalde (2013) in lines 48-49 is because we did not use the Medina-Elizalde (2013) database for this study. We agree that the Medina-Elizalde (2013) database is relevant to the literature review and will reference this study in Section 1. We would also like to note that the "strict" screening criteria is available in the supplementary file that accompanies this manuscript. The WALIS database does not yet have the functionality to accept multiple screening protocols, which is why only the "preferred" criteria is included in the Zenodo file. 
Regarding the comment about spike calibration information, this is indeed included within the file uploaded to Zenodo. It is in the fields titled "Calibration method for $230 \mathrm{Th} / 238 \mathrm{U}$ ratio" and "Calibration method for $234 \mathrm{U} / 238 \mathrm{U}$ ratio" which are columns $\mathrm{BK}$ and $\mathrm{BL}$ in the "U-series (corals)" tab. Perhaps you are referring to columns CP and CQ: "Reference material name for 230Th/238U" and "Reference material name for 234U/238U". These columns, and columns CR-CV were included to address the potential interlaboratory spike calibration biases you referred to. The goal here is that future WALIS users will be able to input a correction factor for the measured 230Th/238U and $234 \mathrm{U} / 238 \mathrm{U}$ activity ratios in the event that such a spike calibration bias is discovered in the future. One example of this is when a laboratory spike has been calibrated to standard that is assumed to be in secular equilibrium, such as the Harwell Uraninite (HU-1). In the case of $\mathrm{HU}-1$, it was later discovered that there were systematic offsets in the Useries isotopic composition of different HU-1 aliquots. There some cases where there is sufficient information in a published manuscript text to perform an ad hoc correction for the $234 \mathrm{U} / 238 \mathrm{U}$ activity ratio (e.g., Chutcharavan et al., 2018). However, the most robust way to perform the correction is by re-measuring the $\mathrm{HU}-1$ aliquot relative to a gravimetrically-calibrated standard, which is outside the scope of the present study. We acknowledge that the spike/decay constant normalization procedure was not explicitly described in the main text and will address this during the revision process.

We agree that the screening protocols applied here do not remove every instance of systematic bias and/or diagenesis and share your concern that accepting the screened data without further evaluation could result in misleading conclusions about sea-level fluctuations within the Last Interglacial Period (LIG). Due to these potential pitfalls, it is of the utmost importance that users consider available stratigraphic and facies evidence when evaluating the quality of the $U$-series ages contained within this dataset, and we have explicitly stated this in the manuscript text. We did not include sealevel interpretations within the manuscript/dataset, as this was outside the scope of the WALIS special issue and Earth System Science Data. 
Finally, we appreciate the suggestions for addressing systematic uncertainties within the dataset. However, we do not believe that adding a uniform systematic error to each age will accurately address the issue, as this assumes that we know the effect of an elevated d234Ui value on a sample's age and that we precisely know the d234U value of Last Interglacial seawater, which we do not. It is true that many samples from certain locations (e.g., Western Australia and Barbados) fall along the Thompson et al. (2003) open-system arrays, but this is not always the case, as shown in Fig. 1 of our preprint text. Therefore, if the d234Ui value is higher than that of the ambient seawater then it may be biased to an older age, but ultimately that depends on the style of open-system behavior. We also would like to clarify that the many of the systematic errors you mentioned are typically already incorporated into the published analytical uncertainties as part of the data reduction process. The U-series community has recently established a set of minimum data reporting standards to minimize such systemic errors (Dutton et al., 2017). We have strived to adhere to these standards when assembling this dataset.

Chutcharavan, P. M., Dutton, A. and Ellwood, M. J.: Seawater 234U/238U recorded by modern and fossil corals, Geochim. Cosmochim. Acta, 224, doi:10.1016/j.gca.2017.12.017, 2018.

Dutton, A., Rubin, K., Mclean, N., Bowring, J., Bard, E., Edwards, R. L., Henderson, G. M., Reid, M. R., Richards, D. A., Sims, K. W. W., Walker, J. D. and Yokoyama, Y.: Quaternary Geochronology Data reporting standards for publication of U-series data for geochronology and timescale assessment in the earth sciences, Quat. Geochronol., 39, 142-149, doi:10.1016/j.quageo.2017.03.001, 2017.

Medina-Elizalde, M.: A global compilation of coral sea-level benchmarks: Implications and new challenges, Earth Planet. Sci. Lett., 362, 310-318, doi:10.1016/j.epsl.2012.12.001, 2013.

Thompson, W. G., Spiegelman, M. W., Goldstein, S. L. and Speed, R. C.: An opensystem model for U-series age determinations of fossil corals, Earth Planet. Sci. Lett.,

Interactive

comment 
210(1-2), 365-381, doi:10.1016/S0012-821X(03)00121-3, 2003.

Interactive comment on Earth Syst. Sci. Data Discuss., https://doi.org/10.5194/essd-2020-381,

ESSDD 2020.

Interactive comment 